\title{
A Hospital Based Study of 2015 Earthquake Injured Patients Attending the Medical College Hospital in Western Region of Nepal
}

\author{
Gupta $S^{1^{*}}$, Shrestha $R^{2}$, Gupta $N^{3}$, Acharya $A^{4}$, Kandel $I^{5}$ \\ ${ }^{1}$ Assistant Professor, Department of General Practice \& Emergency Medicine, \\ Gandaki Medical College \& Teaching Hospital, Pokhara, Nepal \\ ${ }^{2}$ General Practitioner, Bandipur District Hospital, Bandipur, Tanahun, Nepal \\ ${ }^{3}$ MDEVS, Graduate student, Department of Social Engineering, Pokhara University, Pokhara Lekhnath, \\ ${ }^{4}$ Associate Professor, Department of General Practice \& Emergency Medicine, GMCTH \\ ${ }^{5}$ Associate Professor, Department of Orthopedics \& Trauma, GMCTH
}

\author{
Keywords \\ Disaster, Earthquake, Hospital, \\ Morbidity, Nepal.

\section{Corresponding author \\ *Dr. Sandeep Gupta, MD \\ Assistant Professor \\ Department of General Practice and \\ Emergency Medicine \\ Gandaki Medical College \& Teaching \\ Hospital, Pokhara, Nepal \\ E-mail: sandeep140@hotmail.com}

\begin{abstract}
Introduction: On April, 2015, at 11:56 Nepal Standard Time (06:11:26 UTC), a catastrophic earthquake with a magnitude of 7.8 - 8.1 on Richter scale and lasted approximately fifty seconds with Mercalli intensity of IX (Violent) hit the North West of Kathmandu, Nepal. Its epicenter was East of Gorkha District at Barpak, Gorkha, and its hypocenter was at a depth of approximately $8.2 \mathrm{~km}$. It was the worst natural disaster to strike Nepal since the 1934 earthquake. The earthquake caused nearly 9,000 individuals death, injured 22,000 people and 3.5 million people were homeless.
\end{abstract}

Objectives: The main objective of this investigation was to study the demography profile, morbidity pattern, duration of hospital stay and mortality incidence among the 2015 earthquake injured patients visiting Emergency Department of Gandaki Medical College Teaching Hospital.

Methods: A retrospective analysis of the earthquake injured patients attending through the Emergency Department. All the earthquake injured patients attending the Emergency Department from $25^{\text {th }}$ April to $24^{\text {th }}$ May, 2015 were enrolled in our study. The collected data has been complied and analyzed using Statistical Package for the Social Science software package 16 version.

Results: Hundred and seventy patients were triage and 63\% were females. Majority (44.2\%) of patients were of age group of $15-34$ years. Eighty one percent of patients were from Gorkha district, the epicenter site of the earthquake. The three most common diagnoses were trauma and orthopedic injuries (52.4\%), mental health issues and psychological problems $(21.2 \%)$ and reproductive health issues (16\%). Among the $83 \%$ of patients who had been hospitalized, almost $34 \%$ were discharged within one week. Mortality rate was $1.2 \%$.

Conclusions: Since 1993, earthquakes of more than or equal to 5.0 on the Richter scale have occurred in Nepal every year and this makes Nepal $11^{\text {th }}$ most vulnerable country in world. Therefore, every hospital should have well functioning Earthquake Disaster Management Plan to handle this high intensity emergency situation in our country. 


\section{INTRODUCTION}

Earthquake is unpredictable and devastating natural disaster. Since 1993, earthquakes of more than or equal to 5.0 on the Richter scale have occurred every year in Nepal. In 2012, almost 95 earthquakes were reported in Nepal. According to the United Nations, Nepal is the $11^{\text {th }}$ most vulnerable country to earthquakes, and Kathmandu the most at-risk city ${ }^{1}$. Natural Calamity Relief Act, 1982 has formed a Central Natural Disaster Committee chaired by Prime Minister along with Relief and Treatment Subcommittee chaired by Health Minister has formulated number of policies and guidelines for the management of health emergencies and to control the epidemics and outbreaks ${ }^{2}$.

On 25 April, 2015 at 11:56 Nepal Standard Time (06:11:26 UTC), a catastrophic earthquake with a magnitude of 7.8 - 8.1 on Richter scale and lasted 50 seconds with Mercalli Intensity of IX (Violent) hit the North West of Kathmandu, Nepal. Its epicenter was East of Gorkha District at Barpak, Gorkha. It is also known as Gorkha earthquake affected 30 out of 75 districts in Western and Central Regions, including Kathmandu Valley districts. This was the worst natural disaster that killed nearly 9,000 individuals, injured 22,000 people and 3.5 million people were homeless ${ }^{3,4}$. Centuries-old buildings were destroyed at UNESCO world heritage sites in the Kathmandu valley, including some at the Kathmandu Durbar Square, the Patan Durbar Square, the Bhaktapur Durbar Square, the Changu Narayan Temple, the Boudhanath Stupa and the Swayambhunath Stupa. The earthquake triggered an avalanche on Mount Everest and in the Langtang valley, where over 300 people were reported missing ${ }^{5}$.

Natural disaster may occur with or without a warning. A devastating and unpredictable event such as an earthquake becomes alarmingly insurmountable in a resource constrained geographically challenging scenario such as ours in Nepal. Earthquake is a sudden rapid shaking of the earth. Based on a study published in 2014, of the main frontal thrust, on average a great earthquake occurs every $750 \pm 140$ and $870 \pm 350$ years in the East Nepal region ${ }^{6}$. A study from 2015 found a 700 year delay between earthquakes in the region. The study also suggests that because of tectonic stress buildup, the earthquake from 1934 in Nepal and the 2015 quake are connected, following a historic earthquake pattern. A 2016 study on historical great $(M \geq 8)$ earthquake pairs and cycles found that associated great earthquakes are likely to occur in West China region through the $2020^{7,8}$.
The rationale and objective of the paper is to study the demography profile, injury epidemiology after earthquakes by examining injury patterns, treatment, and patient's outcomes based on retrospective analysis of patient's record at the Gandaki Medical College Teaching Hospital, as studies relating to earthquakes related epidemiology are very limited in our country and this is the first disaster related study of our hospital.

\section{METHODS}

This was a retrospective study of earthquake related injured patients which occurred on $25^{\text {th }}$ April 2015 in Nepal. The injured patients attending the Emergency Department of Gandaki Medical College Teaching Hospital from 25 ${ }^{\text {th }}$ April to $24^{\text {th }}$ May, 2015 were enrolled in our study. Approval of this study was obtained from Institutional Ethics Committee and informed consent was taken from the patients or their family members.

The inclusion criteria included the earthquake injured patients visiting the Emergency Department of Gandaki Medical College Teaching Hospital. The collected data was reviewed verified and statistically analyzed using the Statistics Packed for Social Science (SPSS) version 16 and Microsoft Excel 2007. Descriptive statistics was used for all studied variables.

\section{RESULTS}

One hundred and seventy patients were included in the study. Injured patients aged ranged from four days neonates to 89 years. There were 107 females and 63 males. Maximum number of patients (44.2\%) belonged in the age group category of 15 - 34 years (Fig 1). We had patients from 13 different districts of Western Development Region. Eighty one percent of patients were from Gorkha district, the epicenter site of the earthquake followed by Kaski (7.1\%). One International female from France Nationality had undergone treatment at our Hospital. Most common diagnosis in our study (Fig 2) were trauma and orthopedic injuries in 89 (52.4\%), mental health issues and psychological problems were present in $36(21.2 \%)$, reproductive health problems were present in $27(16 \%)$ of them 14 patients were pregnant and one of them had normal delivery at our Hospital, Infectious diseases 11 (6.5\%) and non communicable diseases seven $(4.1 \%)$. 
Fig 1: Age and gender distribution of earthquake injured patients

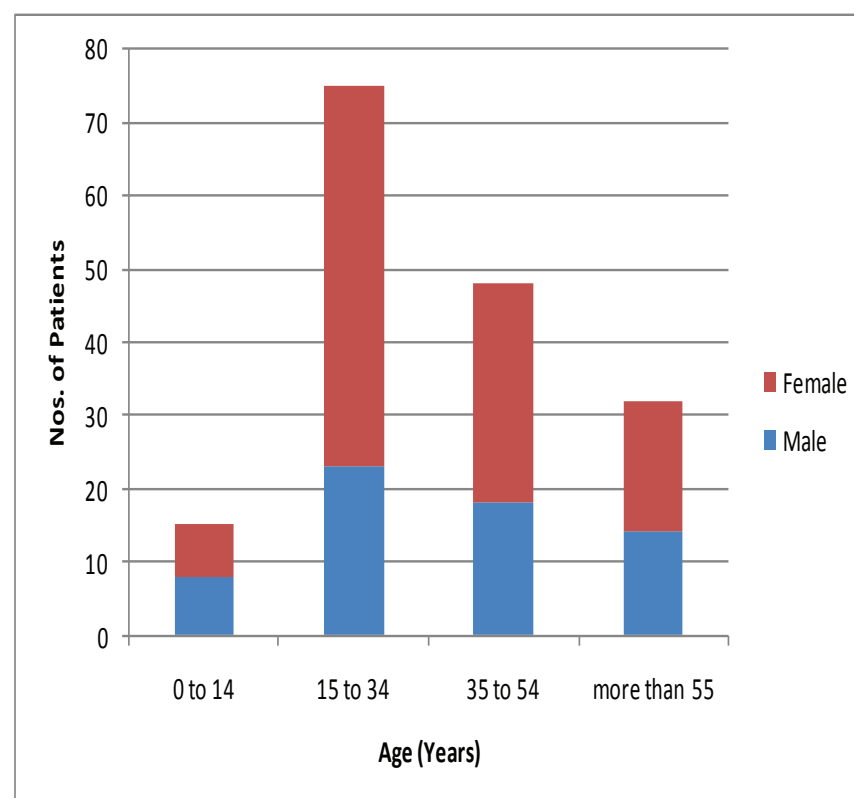

Fig 2: List of diagnosis of the earthquake injured patients

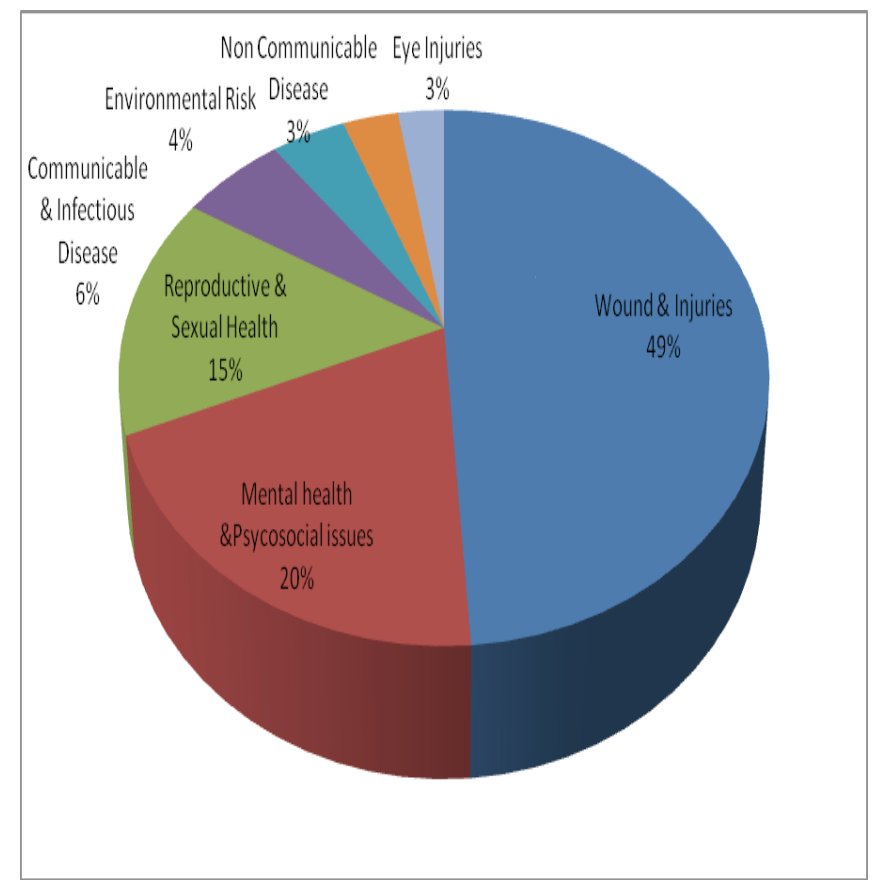

Figure 3 shows the duration of hospital stays of the earthquake injured patients at Gandaki Medical College Teaching Hospital. Almost $34 \%$ of patients were discharged within one week followed by $25.6 \%$ within three days. Six percent of patients stayed for more than two weeks duration at our hospital. Four of our patients were referred to Kathmandu on family request and two mortalities had occurred while undergoing treatment at our Hospital.
Fig : 3 : Duration of hospital stay

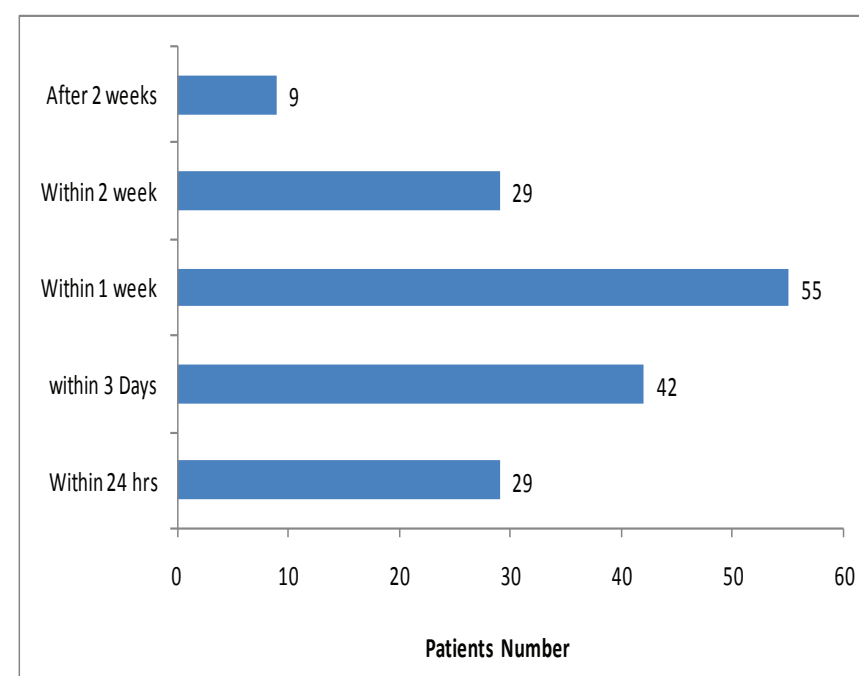

\section{DISCUSSION}

Every major disaster warrants retrospective studies so that we can learn how to improve all levels of emergency medical care. Lack of precise data from immediate aftermath is seen as a remarkable weak point in disaster epidemiology $y^{9,10}$. Management of earthquake aftermath is a complex and challenging. The causality rates of earthquake is one to eight percent, however the number of causality dependents on magnitude, proximity to populated areas, geographic topology, time and duration of the earthquake, degree of disaster preparedness implemented at the earthquake affected area. In 2005, a hypothetical scenario earthquake near Kathmandu for 8.1 Richter scale had expected numbers of fatalities between 21,000 and $42,000^{11}$.

The 2015 April/May earthquake killed more than 8,800 people and injured nearly three times as many and almost 3.5 million people were left homeless ${ }^{3}$. It killed only about 10,000 people because it was Saturday and the children were not in the collapsing school buildings. This saved the lives of about 10,000 children. The original estimate was correct within a factor of 2.5 and would have been exactly correct, had it not been for the lucky break children got due to Saturday being a holiday ${ }^{12}$.

The study showed female to male ratio of $1.7: 1$, involving almost $63 \%$ of females. The age group of our patients varied from four days neonates to 89 years old individuals. There were total of four infants below one year of age. Highest number $((44.2 \%)$ of individuals belonged within the category of 15 - 35 years age group. This age group is the most commonly involved population during 
earthquake would be more likely been active population in the community. Our findings were similar with two studies done from Gujarat reported more female patients than males ${ }^{13}$. In our study we had 15 pregnant mothers and one had delivered at our Hospital after admission in the maternity ward.

Our findings showed trauma and orthopedic injuries of $52.4 \%$ were in similar with other earthquake studies reporting higher incidence of orthopedics injuries particularly extremities fractures ${ }^{14,15,16}$. Mental health issues and psychological problems (21.2\%) were second in the list with reproductive health problems (16\%). The findings were similar with Tanaka et $a{ }^{17}$ done in HanshinAwaji earthquake study of 1995 . The noticed crush injuries and trauma, respiratory diseases, cardiovascular diseases, obstetrics complications most commonly.

The average duration of hospital stay in our study patients was less than one week, although patient's hospital stay duration varied from within 24 hours to 2 months. About $34 \%$ of patients had been discharged within less than one week period. Within 24 hours period 29 (17.7\%) patients was discharged. Duration of hospital stay after the disaster is an important variable particularly to measure the humanitarian response strategies within the countries.

\section{CONCLUSIONS}

Our country Nepal lies in the earthquake prone region within the Southern limit of the diffuse collisional boundary where the Indian Plate under thrusts the Eurasian Plate, occupying the central sector of the Himalayan region. Earthquake and other disasters can have a serious impact in the developing countries like ours. Hospitals need to develop, practice and continuously update an effective disaster/ emergency medical response plan and also perform a mock drill at least once every year. Therefore it is recommended for every Institute to be prepared for immediate response and mobilize the hospital personnel in effective way to meet the needs of the affected populations at the time of an earthquake and other disasters. Lastly we would like to recommend for earthquake response training and capacity building activities for our health workers throughout the country to specialize their skills in management of large numbers of victims with a spectrum life threatening injuries emergently.

\section{Acknowledgement}

We would like to give heartfelt thanks to all the staff of Emergency Department including Mr. Jay Prakash Kori and Mr. Surya Bhadur Thapa, Nepal Police personnel posted in the Emergency Department for helping us in the study.

\section{Conflict of Interest}

The authors declare that they have no competing interests and have not received any funding or benefits to conduct this study.

\section{REFERENCES}

1. Nepal earthquakes, April and May 2015. European Commission- Humanitarian Aid and Civil Protection. http://ec.europa.eu/echo/files/aid/countries/ factsheets/nepal_en.pdf//

2. Natural Calamity (Relief) Act. 2039 B.S. (1982).// www.nrcs.org/sites/default/files/pro-doc/naturalcalamity-relief-act.pdf//

3. Incident Report of Earthquake 2015. Nepal Disaster Risk Reduction Portal. //www.drrportal.gov.np//.

4. Powerful earthquake hits Nepal. Al Jazeera News.

5. Kaini S. Great Earthquake wipes out Barpak. The Kathmandu Post.

6. Bollinger L et al. Return period of great Himalayan earthquakes in Eastern Nepal: Evidence from the Patu and Bardibas strands of the Main Frontal Thrust. Jou of Geophysical Res. 2014; 119(9): 7123-7163.

7. Nepal quake followed historic pattern. BBC.

8. Ke-Pei M, Kai Z. The 2015 Nepal M 8.1 earthquake and the prediction for $M \geq 8$ earthquakes in West China. Nat. Hazards. 2016; 82(3): 1767-77.

9. Guha-Sapir D, Vos F. Chapter 2: Earthquakes, an epidemiological perspective on patterns and trends. In: Spence R, So E, Scawthorn C, eds. Human casualties in earthquakes: progress in modelling and mitigation. New York: Springer; 2011 pp. 13-24.

10. Lechat MF. The epidemiology of health effects of disasters. Epidemiol Rev. 1990; 12: 192-8.

11. Wyss M. Human losses expected in Himalayan earthquakes. Nat. Hazards. 2005; 34: 305-314. 
12. April 2015 Nepal earthquake. //en.wikipedia.org/ wiki/

13. Phalkey R, Reinhardt JD, Marx M. Injury epidemiology after the 2001 Gujarat earthquake in India: A retrospective analysis of injuries treated at a rural hospital in the Kutch district immediately after the disaster. Global Heat Act. 2011; 4: 7196.

14. Dhar SA et al. The Kashmir earthquake experience. Eur J Trauma Emerg Surg. 2007; 33: 74-80.

15. Motamedi MHK, Saghafinia M, Bafarani H, Panahi F. A Reassessment and review of the Bam earthquake five years onwards: What was done wrong? Prehosp Disaster Med. 2009; 24(5): 453-460
16. Şehitogulları A, Kahraman A, Sayır F, Akın O, Sevilgen G, Çobanoglu U. Clinical profile of thorax and lung injuries associated with the 2011 Van Earthquake in Turkey. Eur J Gen Med. 2013; 10(2): 69-73.

17. Tanaka $\mathrm{H}$ et al. Morbidity and mortality of hospitalized patients after the 1995 Hanshin- Awaji earthquake. American J Emer Med. 1999; 17(2): 186-90. 